Dicle University Journal of Engineering (DUJE)

Araştırma Makalesi / Research Article

\title{
Ti6A14V Alaşımına Sol-Jel Yöntemi ile Yapılan Hidroksiapatit Kaplamalarda Dietanolaminin Kaplama Morfolojisine ve Korozyon Dayanımına Etkisi
}

\author{
Effect of Dietanolamine on Coating Morphology and Corrosion Resistance in \\ Hydroxyapatite Coatings Made by Sol-Gel Method on Ti6Al4V Alloy \\ Canser Gül $^{1 *}$, Serhat Mutaf ${ }^{2}$, Hülya Durmuş ${ }^{3}$ \\ ${ }^{1}$ Manisa Celal Bayar Üniversitesi, Metalurji ve Malzeme Mühendisliği, Manisa, ORCID: 0000-0002-1339-936X, canser.gul@cbu.edu.tr \\ ${ }^{2}$ Manisa Celal Bayar Üniversitesi, Metalurji ve Malzeme Mühendisliği, Manisa, ORCID: 0000-0003-0502-7176, mutafserhat@ gmail.com \\ ${ }^{3}$ Manisa Celal Bayar Üniversitesi, Metalurji ve Malzeme Mühendisliği, Manisa, ORCID: 0000-0002-7270-562X, hulya.durmus@cbu.edu.tr
}

\begin{tabular}{l} 
MAKALE BİLGİLERİ \\
\hline Makale geçmişi: \\
Geliş: 28 Mart 2020 \\
Düzeltme: 10 Mayıs 2020 \\
Kabul: 12 Mayıs 2020 \\
\hline Anahtar kelimeler: \\
Ti6Al4V, Sol-jel, Biyomalzemeler, \\
Hidroksiapatit, Dietanolamin
\end{tabular}

Hidroksiapatit, Dietanolamin

\begin{abstract}
ÖZET
Titanyum ve alaşımları, mekanik dayanımları ve biyotolerant yapıda olmaları nedeni ile biyomalzeme uygulamalarında tercih edilirler. Fakat insan vücudu içinde korozyona uğraması durumunda zararlı iyonların salınımına neden olabilirler. Hidroksiapatit ise seramik ve biyoaktif yapıda bir malzeme olup biyomalzemelerin korozyon dayanımlarını arttırmaya yönelik kaplama tabakası olarak kullanımı da mevcuttur. Bu çalışmada Ti6A14V alaşımının korozyon dayanımını geliştirmek amacı ile sol-jel yöntemi kullanılarak hidroksiapatit kaplamalar yapılmıştır. Hazırlanan hidroksiapatit solüsyonlarına farklı oranlarda dietanolamin (DEA, $\mathrm{C}_{4} \mathrm{H}_{11} \mathrm{NO}_{2}$ ) eklenerek sol-jel prosesinde oluşması muhtemel olan çatlaklı yapılar kontrol edilmiş ve azaltılmaya çalışılmış ve kaplamanın genel morfolojisinde ve korozyon dayanımında meydana gelen değişikliklerin gözlemlenmesi amaçlanmıștır. Numuneler taramalı elektron mikroskobu (SEM-EDS) ve X-Işını kırınımı (XRD) kullanılarak analiz edilmiştir. Hazırlanan yapay vücut sıvısı içinde elektrokimyasal-potansiyodinamik korozyon testleri gerçekleştirilmiştir. Çalışmanın sonucunda DEA katkı oranının artması ile morfolojide çatlaklı yapıların azaldığı ve kaplama kalınlığının arttığı gözlemlenmiş̧tir. DEA eklenmesinin korozyon dayanımını arttırdığı fakat DEA miktarındaki artışın korozyon dayanımını negatif etkilediği görülmüştür.
\end{abstract}

Doi: 10.24012/dumf.710557

\begin{tabular}{|c|c|}
\hline ARTICLE INFO & ABSTRACT \\
\hline Article history: & \multirow{6}{*}{$\begin{array}{l}\text { Titanium and its alloys are preferred in biomaterial applications due to their mechanical strength and biotolerant } \\
\text { structure. However, if they are corroded in the human body, they can cause the release of harmful ions. } \\
\text { Hydroxyapatite is a ceramic and bioactive material, and it is also used as a coating layer for increasing the } \\
\text { corrosion resistance of biomaterials. In this study, hydroxyapatite coatings were made using the sol-gel method } \\
\text { to improve the corrosion resistance of Ti6Al4V alloy. By adding different ratios of diethanolamine (DEA, } \\
\mathrm{C}_{4} \mathrm{H}_{11} \mathrm{NO}_{2} \text { ) to the prepared hydroxyapatite solutions, cracked structures that are likely to occur in the sol-gel } \\
\text { process has been checked and tried to be reduced. It has been aimed to observe the changes in the overall } \\
\text { morphology and corrosion resistance of the coatings. Samples were analyzed using scanning electron } \\
\text { microscopy (SEM-EDS) and X-Ray diffraction (XRD). Electrochemical-potentiodynamic corrosion tests were } \\
\text { carried out in the prepared simulated body fluid. As a result of the study, it was observed that the cracked } \\
\text { structures and the coating thickness increased in morphology with the increase in the DEA contribution rate. It } \\
\text { was seen that the addition of DEA increases the corrosion resistance, but the increase in the amount of DEA } \\
\text { negatively affects the corrosion resistance. }\end{array}$} \\
\hline Received: 28 March 2020 & \\
\hline Revised: 10 May 2020 & \\
\hline Accepted: 12 May 2020 & \\
\hline Keywords: & \\
\hline $\begin{array}{l}\text { Ti6Al4V, Sol-gel, Biomaterials, } \\
\text { Hydroxyapatite, Diethanolamine }\end{array}$ & \\
\hline
\end{tabular}

\footnotetext{
* Sorumlu yazar / Correspondence

Canser GÜL

$\triangle$ canser.gul@cbu.edu.tr
} 


\section{Giriş}

Titanyum ve alaşımları yüksek korozyon dayanımları ve mekanik özellikleri nedeni ile biyomalzeme uygulamalarında siklıkla kullanılmaktadır $[1,2]$. Kullanılan diğer metalik biyomalzemeler ile kıyaslandığında, paslanmaz çeliklere ve kobalt-krom alaşımlarına göre her ne kadar vücut ile etkileşimleri daha olumlu olsa da [3], kemik dokusunun entegrasyonu için önemli olan biyoaktiflik özelliğini göstermezler $[2,4]$.

Hidroksiapatit (HA, $\left(\mathrm{Ca}_{10}\left(\mathrm{PO}_{4}\right)_{6}(\mathrm{OH})_{2}\right)$ kemik ve dişlerde doğal olarak bulunan, 1,67 sitokiyometrik oranında Ca kalsiyum ve fostor elementlerini başlıca içeren bir kalsiyumfosfattır [5]. Bileşenlerinin bu denli kortikal kemiğe yakın olması, biyoaktiflik özelliğinin artmasına ve titanyum ve alaşımlarının gösteremediği osseointegrasyon özelliğini gösterebilmesini sağlamaktadır [6]. HA kaplama, titanyum ve alaşımları üzerine plazma sprey [7], sol-jel yöntemi [8], mikro ark oksidasyonu [9], darbeli lazer birikimi [10], elektroforez [11], hidrotermal-elektrokimyasal [12] yöntem ve benzeri çeşitli yöntemler kullanarak uygulanabilmektedir. $\mathrm{Bu}$ yöntemler arasında sol-jel yöntemi parametrelerin kolay kontrol edilebilmesi ve değiştirilebilmesi, çok çeşitli ve karmaşık şekilli parçalara uygulanabilmesi avantajını sağlaması, kaplama kalınlığının kolay ayarlanabilir olması, yüksek kimyasal saflıkta kaplama elde edilebilmesi ve ilk yatırım maliyetinin düşük olması gibi avantajlara sahiptir $[13,14]$.

Uzun yıllardan beri çeşitli kaplama tabakaları sol-jel metodu kullanılarak elde edilmektedir. $\mathrm{Bu}$ metodun genel aşamaları jel oluşumu, yaşlandırma, kurutma ve sinterleme olarak nitelendirilmektedir [15]. Elde edilen silika jelini 1slak halden direkt olarak kurutarak bir silika monolit elde etmek oldukça zordur. Eğer bu işlem kontrollü bir biçimde gerçekleştirilmezse kurutma prosesleri sırasında yapıda yüksek oranda çatlaklar meydana gelmektedir [16, 17]. Kurutma işlemi sırasında çözücülerin ve diğer düşük buharlaşma sıcaklığına sahip bileşenlerin uzaklaştırılması ile kapiler bir basınç meydana gelmektedir. Kapiler basınç kaplama solüsyonu ve altlık malzeme arasındaki yüzey gerilimine, yüzeyler arasında oluşan temas açısına ve solüsyonda mevcut gözeneklerin boyutuna bağlıdır. Kurutma işlemi sırasında oluşan gerilmeler ve büzülmeler sonucunda çatlaklar oluşmaktadır [15]. Haddow vd. [18], daldırma hızı, sinterleme sicaklıkları ve sinterleme süresinin sol-jel yöntemi ile titanyum üzerine yapılan kaplamalara etkisini inceledikleri çalışmalar yapmışlardır. Aynı zamanda kullandıkları dietanolamin ile sinterleme sırasında ortaya çıkabilecek çatlakları en aza indirmeyi hedeflemişlerdir. Yaptıkları çalışmanın sonucunda düşük ve yüksek daldırma hızlarında yapılan sinterleme işleminde, sıcaklığa bakılmaksızın dietanolamin eklenmesinin filmlerde çatlamayı azalttığını tespit etmişlerdir. Yaşlandırma işlemi ile de jelin mekanik mukavemetini artırmak veya kurutma kontrol kimyasalları gibi organik bileşenler kullanılarak, gözenekli ve çatlaklı yap1 engellenebilmektedir [15]. Ayrıca, termal genleşme katsayıları genellikle farklı olan altlık malzeme ve kaplama tabakası arasında bir ara katman görevi üstlenerek, kurutma ve sinterleme aşamalarında genleşme farklılıkları nedeni ile oluşacak veya büyüyecek olan çatlakları engellemek amacıyla da ara katman olarak veya silika içerikli bu ara tabakalara eklenerek kullanımları da mevcuttur [19].

Yapılan bu çalışmada, Ti6Al4V alaşım numunelerinin üzerine sol-jel yöntemi kullanılarak hidroksiapatit kaplamalar yapılmıştır. Sol-jel yönteminde oluşması muhtemel çatlaklı yapıların azaltılabilmesi için hazırlanan solüsyona farklı miktarlarda DEA eklenmiştir. Toplamda 5 farklı oranda kimyasal içeren, farklı hidroksiapatit çözeltileri kullanılarak kaplamalar yapılmıştır. $\mathrm{Bu}$ solüsyonların, kaplama morfolojilerine etkileri taramalı elektron mikroskobu (SEM-EDS) ve X-Işını Kırınımı (XRD) kullanılarak incelenmiştir. Vücut içinde kullanıldığında 
implantın korozyon dayanımını da geliştirmesi beklenen bu kaplamalar, karakterize edildikten sonra elektrokimyasal-potansiyodinamik korozyon testlerine de tabi tutulmuş ve simüle edilmiş insan vücudu içinde in-vitro ortamda korozyon dayanımları incelenmiştir.

\section{Malzeme ve Metot}

Uygun boyutlarda kesilen Ti6Al4V (GR5) altlik numuneler 180 grid SiC zımparalar kullanılarak mekanik olarak zımparalanmıştır. Daha sonra numuneler ultrasonik banyoda aseton ve etanol kullanılarak temizlenmiş ve 5M'lik hazırlanan $\mathrm{NaOH}$ çözeltisi içine konulmuştur. Yüzeylerindeki oksit tabakasının kırılması için $50{ }^{\circ} \mathrm{C}$ sicaklıkta bu solüsyon içinde 24 saat bekletilmiştir. $\mathrm{Bu}$ işlem ile yüzey aktifleştirilmiştir.

Hidroksiapatit çözeltisi iki farklı ana bileşen kullanılarak hazırlanmıştır. Kalsiyum nitrat tetrahidrat $\left(\mathrm{Ca}\left(\mathrm{NO}_{3}\right)_{2} .4 \mathrm{H}_{2} \mathrm{O}\right)$ ve di-fosfor pentaoksit $\left(\mathrm{P}_{2} \mathrm{O}_{5}\right)$ ayrı ayrı etanol içinde $15 \mathrm{dk}$ çözdürülmüştür. $\mathrm{Bu}$ işlemden sonra kalsiyum içerikli solüsyon fosfor içerikli solüsyon içine damla damla eklenmiştir. Sonrasında oda sıcaklığında karıştırılan solüsyon katkı kimyasalları karıştırılmak üzere 5 farklı cam kaba ayrılmıştır. İlk solüsyon hiç katkı maddesi içermeyen HA solüsyonu olup $\mathrm{S}$ olarak isimlendirilmiştir. Diğer solüsyonlar ise sirasiyla hacimce \% 1, 2, 3, 4 oranlarında DEA içermektedir ve sırasıyla D1, D2, D3 ve D4 şeklinde isimlendirilmiştir. Hazırlanan tüm solüsyonlar oda sicaklığında 5 saat karıştırıldıktan sonra saydam şeffaf renkte gözlemlenmiş, 48 saat oda sıcaklığında karıștırılmadan bekletilmiş ve sonrasında kaplamaya hazır hale gelmiştir.

Yüzey aktifleștirilen numuneler hazırlanan çözeltilere PTL-MM01 daldırmalı kaplama cihazı kullanılarak dikey bir şekilde daldırılmış ve 60 s solüsyon içinde bekletildikten sonra aynı şekilde geri çekilmiştir. Daldırma hızı 100 $\mathrm{mm} / \mathrm{dk}$ olacak şekilde daldırılan numuneler kaplandiktan sonra $1{ }^{\circ} \mathrm{C} / \mathrm{dk}$ hiz ile isınan etüv içinde $50{ }^{\circ} \mathrm{C}$ sicaklıkta $30 \mathrm{dk}$ kurutulmuş, sonrasında $400{ }^{\circ} \mathrm{C}$ 'de 1 saat süre ile sinterlenmiş ve firın içinde soğumaya bırakılmıştır. Kaplama işlemi akış şeması Şekil 1'de gösterilmiştir.

Kaplanmamış ve farklı oranlarda kurutma kontrol kimyasalları içeren hidroksiapatit solüsyonları ile kaplanmış Ti6A14V numunelerin yüzey morfolojileri ZEISS Gemini 500 taramal1 elektron mikroskobu (SEM) ile analiz edilmiştir. $\mathrm{Bu}$ cihaza ait enerji dağılımı spektrometresi (EDS) ile noktasal ve bölgesel EDS analizleri yapılmış ve kaplamaların kimyasal değişimleri bu şekilde gözlemlenmiştir. Görüntüleme sırasında 5 ve 10 $\mathrm{kV}$ hızlandırma gerilimleri kullanılmıştır.

Kaplama kalınlıklarının belirlenmesinde ise Minitest 650 kaplama kalınlığı ölçüm cihazı kullanılmıştır.

Kaplanmış numunelerin X-1şını analizleri Bruker D8 Advance marka X-Ișını Difraktometresi (XRD) ile yapılmıştır. Saniyede

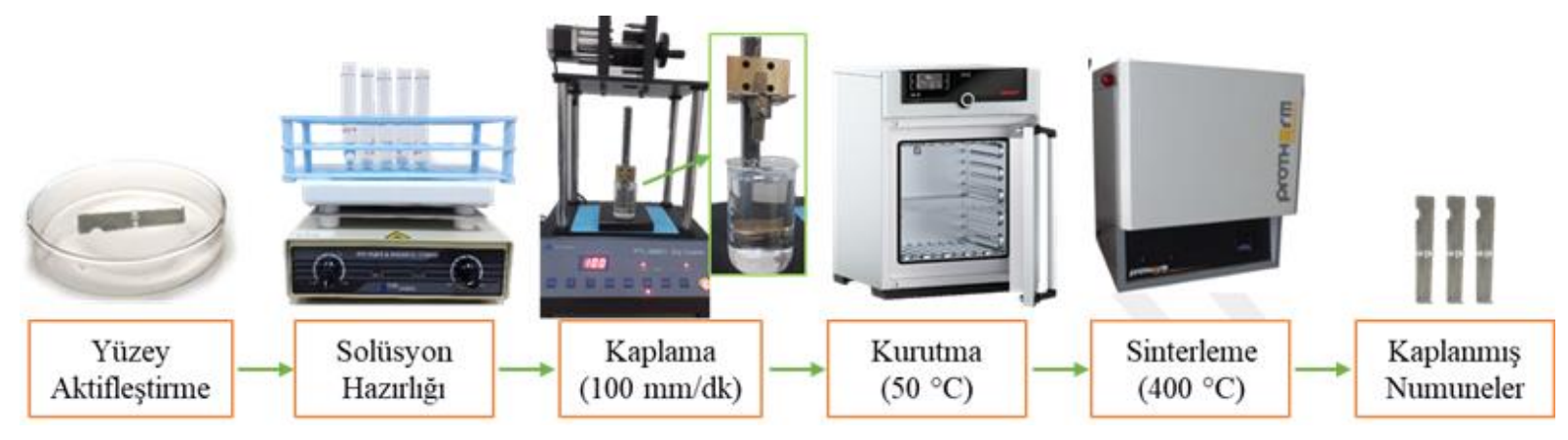

Şekil 1. Sol-Jel prosesi akış şeması

Figure 1. Sol-Gel process flow chart 
$0,03^{\circ}$ derece tarama hizında $\mathrm{CuK} \boldsymbol{\alpha}(\boldsymbol{\lambda}=1,5418$ Å) 1şını, $30 \mathrm{~mA}$ akım ve $40 \mathrm{~V}$ voltaj kullanılmıştır. Taramalar $30-90^{\circ}$ aralığında ayarlanmış ve yapısal analizler bu şekilde gerçekleştirilmiştir.

\section{Korozyon deneyleri, Metrohm} galvanostat/potansiyotat $\mu$ stat 400 ile, çalışma elektrodu olarak $1 \mathrm{~cm}^{2}$ yüzey alanına sahip kaplanmış numune yüzeyi, karşı1 elektrot olarak grafit elektrot ve referans elektrodu olarak doymuş kalomel elektrot içeren üç elektrotlu sistem kullanılarak gerçekleştirilmiştir. Üretilen numunelerin korozyon davranışlarını incelemek için insan vücudunda bulunan ortam simüle edilmiş ve korozyon deneyleri insan vücudunda bulunan sıvı ile eşdeğer miktarda bileşenleri içeren yapay vücut sıvısı (SBF) hazırlanarak, 37 ${ }^{\circ} \mathrm{C}$ sicaklikta ve $7,4 \mathrm{pH}$ değerinde gerçekleştirilmiştir. Numunelere $-500 \mathrm{mV}$ ve $500 \mathrm{mV}$ aralığında $1 \mathrm{mV} / \mathrm{s}$ hızda elektrokimyasal tarama yapılmıştır. Her bir ölçüm öncesi 5 dakika süre ile açık devre potansiyeli ölçülmüştür.

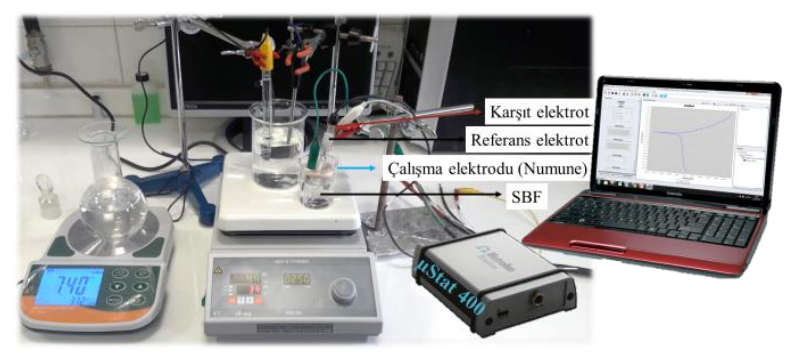

Şekil 2. Korozyon testi deney düzeneği

Figure 2. Corrosion test rig

SBF hazırlanırken, Pasinli vd. [20], insan vücut sıvısına en yakın özellikteki bileşimi hazırladıklarını vurguladıkları çalışmada kullandıkları yöntem kullanılmıştır. 1 litre çözelti için; 6,547g NaCl, 2,268g $\mathrm{NaHCO}_{3}$, $0,378 \mathrm{~g} \mathrm{KCl}, 0,178 \mathrm{~g} \quad \mathrm{Na}_{2} \mathrm{HPO}_{4} .2 \mathrm{H}_{2} \mathrm{O}, 0,305 \mathrm{~g}$ $\mathrm{MgCl}_{2} \cdot 6 \mathrm{H}_{2} \mathrm{O}, \quad 0,368 \mathrm{~g} \quad \mathrm{CaCl}_{2} \cdot 2 \mathrm{H}_{2} \mathrm{O}, \quad 0,071 \mathrm{~g}$ $\mathrm{Na}_{2} \mathrm{SO}_{4} \quad$ ve $\quad 6,057 \mathrm{~g} \quad\left(\mathrm{CH}_{2} \mathrm{OH}\right)_{3} \mathrm{CNH}_{2}$ kullanılmıştır. Son bileşenin ilave edilip tamamen çözündürülmesinin ardından $\mathrm{pH}$, hazırlanan $1 \mathrm{M} \mathrm{HCl}$ çözeltisi kullanılarak 7,4'e ayarlanmıştır. $\mathrm{Bu}$ yöntem ile vücut içinde mevcut bileşime en yakın bileşim elde edilmiş ve korozyon deneylerinde de hazirlanan bu çözelti kullanılmıştır. Hazırlanan deney düzeneği Şekil 2'de gösterilmiştir.

\section{Bulgular ve Tartışma}

Katkı maddesi içermeyen, HA ile kaplanmış S numunesine ait SEM-EDS görüntüsü ve sirasiyla hacimce $\% 1,2,3,4$ oranlarında DEA içeren HA ile kaplanmış numunelere ait SEM görüntüleri Şekil 3'te gösterilmiştir. Sadece HA içeren kaplama tabakası incelendiğinde yüzeyde kaplama adacıkları, DEA kullanılarak engellenmek istenen çatlaklar görülmektedir. Wang ve Bierwagen [19], çalışmalarında da benzer çatlaklı yapılara rastlanmıştır. Sol-jel yönteminde solüsyon içerisinde bulunan su ve çözücüler gerçekleştirilen kurutma ve sinterleme işlemleri sırasında yapıdan uzaklaşmaktadır ve bu durumun kontrolünü direkt olarak sağlamak mümkün olmadığı için bu çatlaklara rastlanabilmektedir [13].

Şekil 3.a'da verilen EDS analizi verileri incelendiğinde 1 numaralı bölge $\mathrm{HA}$ ana bileşenleri olan $\mathrm{Ca}$, $\mathrm{P}$ ve $\mathrm{O}$ içermektedir. Bunun yanı sıra altlık malzemesinden geldiği düşünülen $\mathrm{Na}$ ve Ti piklerinden de bir miktar gözlemlenmiştir. 2 numaralı noktasal EDS, diğer tabakalara göre daha pürüzlü olan bir bölgeden alınmıştır. Ayrıca kaplama tabakasına ait olduğu ve başlıca $\mathrm{Ca}, \mathrm{P}$ ve $\mathrm{O}$ elementlerini içerdiği görülmüştür. 3 numaralı bölge çatlamış ve ayrılmış kaplama adacıklarının aralarındaki kısımlardan alınmış ve beklendiği gibi Ti ve $\mathrm{O}$ elementlerini büyük oranda içerdiği gözlemlenmiştir. Altlık malzemesi olarak kullanılan Ti6A14V alaşımı yüzey aktifleștirme işlemi sırasında $\mathrm{NaOH}$ içinde bekletilmiş ve sonrasında kaplama işlemine tabi tutulmuştur. $\mathrm{Bu}$ durum sonrasında yüzeye tam olarak tutunamayan kaplama tabakaları kuruma sırasında farklı sebepler ile çatlamış ve bu çatlakları oluşturmuştur. Çatlayan kısımlar ise yüzey aktifleştirme işleminin ve sıcaklığın da etkisi ile titanyumun oksitlenmesine neden olmuştur. Bu nedenle çatlak bölgelerde Ti, Al 


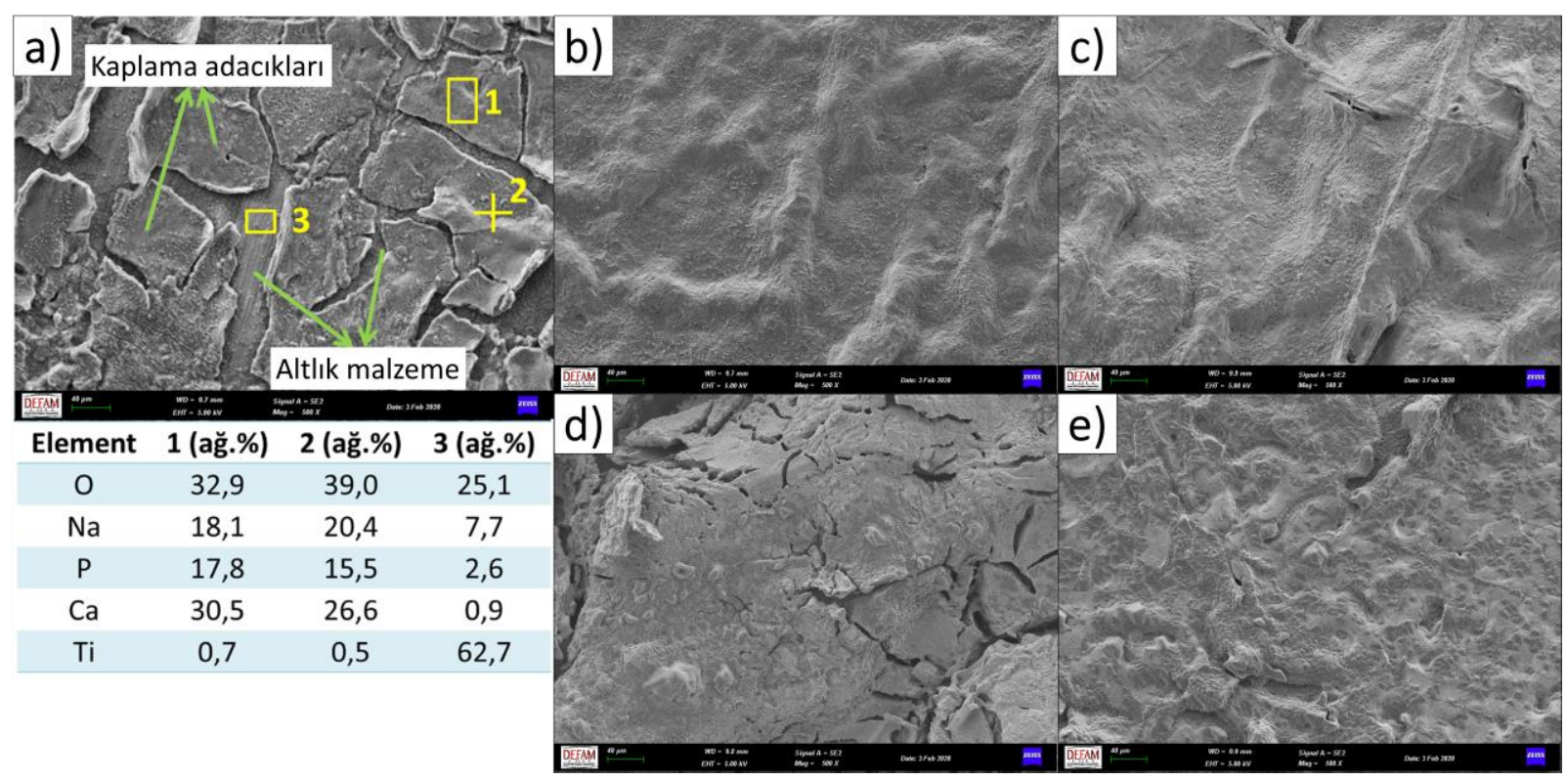

Şekil 3. HA ile kaplanmış $S$ numunesine ve sırasılyla hacimce \% 1, 2, 3, 4 oranlarında DEA içeren, a) $S$, b) D1, c) D2, d) D3 ve e) D4 numunelerine ait SEM görüntüleri

Figure 3. a)SEM-EDS image of S sample coated with HA and SEM images of b) D1, c) D2, d) D3 and e) D4 samples containing 1, 2, 3, 4 wt. \% DEA respectively.

ve $\mathrm{V}$ elementlerinden ziyade $\mathrm{Ti}$ ve $\mathrm{O}$ elementleri gözlemlenmiştir. Şekil 3.b'de DEA eklenmesi ile numunedeki çatlamaların çok büyük ölçüde önlendiği gözlemlenmiştir. SEM görüntüleri incelendiğinde DEA miktarındaki artış ile kaplama kalitesinin arttığı söylenemez. Fakat Şekil 3. b, c, d ve e numunelerinin hiç biri DEA eklenmemiş numune kadar çatlaklı bir yapıya sahip değildir.

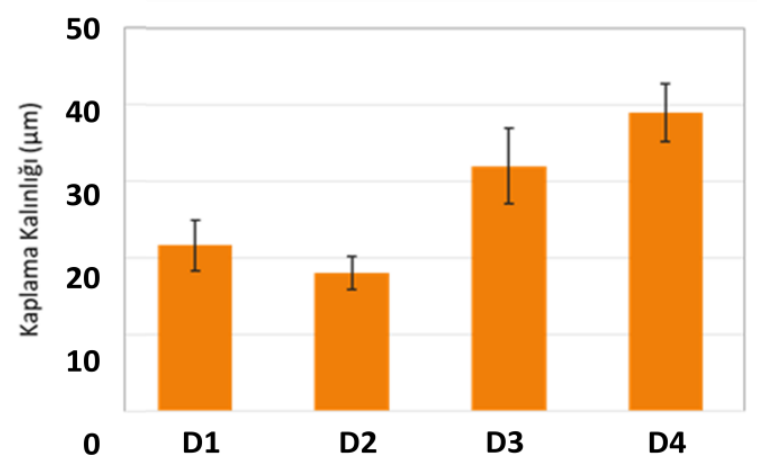

Şekil 4. Kaplama kalınlıkları

Figure 4. Coating thicknesses
Şekil 4'te kaplama kalınlıkları verilmiştir. S numunesi çatlaklı bir yapı içerdiğinden kaplama kalınlığı doğru sonuçlar vermemiş ve bu nedenle ölçüm grafiğinde verilmemiştir. DEA içerikli numuneler incelendiğinde, kaplama kalınlıklarının artmasının sebebi DEA miktarının artması ile solüsyonun daha yoğun bir şekilde elde edilmesi olarak gösterilebilir. $\mathrm{Bu}$ durum, kaplama kalınlığını arttırdığı gibi, kaplama tabakasının tutunabilirliğinin azalmasına ve bazı bölgelerde kaplama adacıklarının kenar kısımlarının havaya kalkmasına da neden olduğu da düşünülmektedir. $\mathrm{Bu}$ durum ise Şekil $3 . \mathrm{d}$ ve e'de bazı bölgelerde gözlemlenen mikro çatlaklar ile ilişkilendirilebilir.

Şekil 5'te Ti6Al4V altlık malzemesine ait XRD grafiği verilmiştir. Ti6Al4V numunesi ICDD kart numaraları sirasiyla 44-1294 ve 44-1288 olan $\boldsymbol{\alpha}$-Ti ve $\boldsymbol{\beta}$-Ti fazlarını içermektedir. 


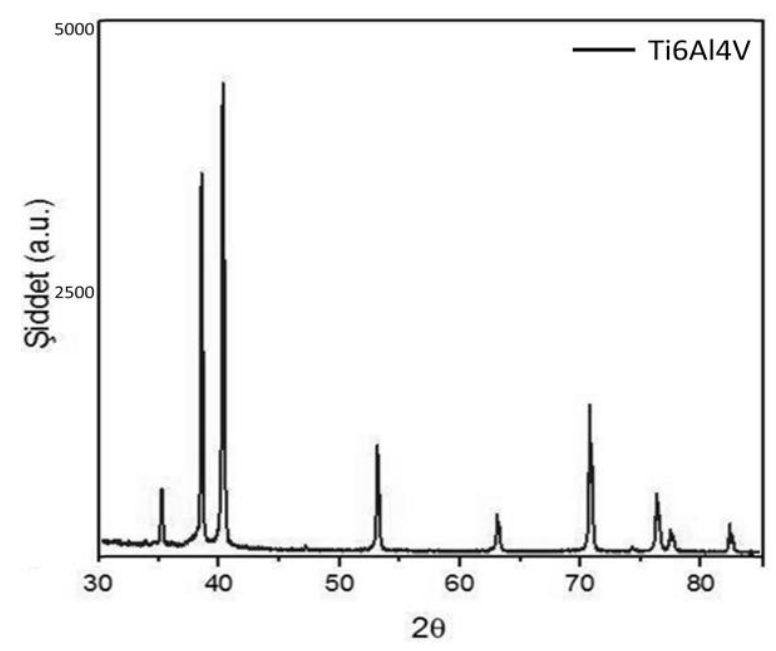

Şekil 5. Ti6Al4V altlı̆̆a ait XRD grafiği

Figure 5. XRD graphic of Ti6Al4V substrate
Farklı oranlarda DEA içeren D1, D2, D3, D4 ve DEA içermeyen $S$ numunelerine ait XRD grafiği Şekil 6'da görülmektedir. Altlık malzemesinden gelen piklerin şiddetlerinin kaplama kalınlığının artması ile bir miktar azaldığ 1 görülmüştür. Arafat vd. [21], yaptıkları çalışmada Ti6Al4V alaşımının farklı sıcaklıklardaki termal oksitlenme davranışlarını incelemiş ve sıcaklığın etkisi ile yapıda $\boldsymbol{\alpha}$-Ti ve $\boldsymbol{\beta}$-Ti fazlarının haricinde oksitli fazlar da gözlemlemiştir. Gözlemlenebilecek oksitli fazlar DEA içerikli solüsyon ile kaplanmış numunelerin XRD analizleri ile kıyaslanmış fakat oksitli herhangi bir pik

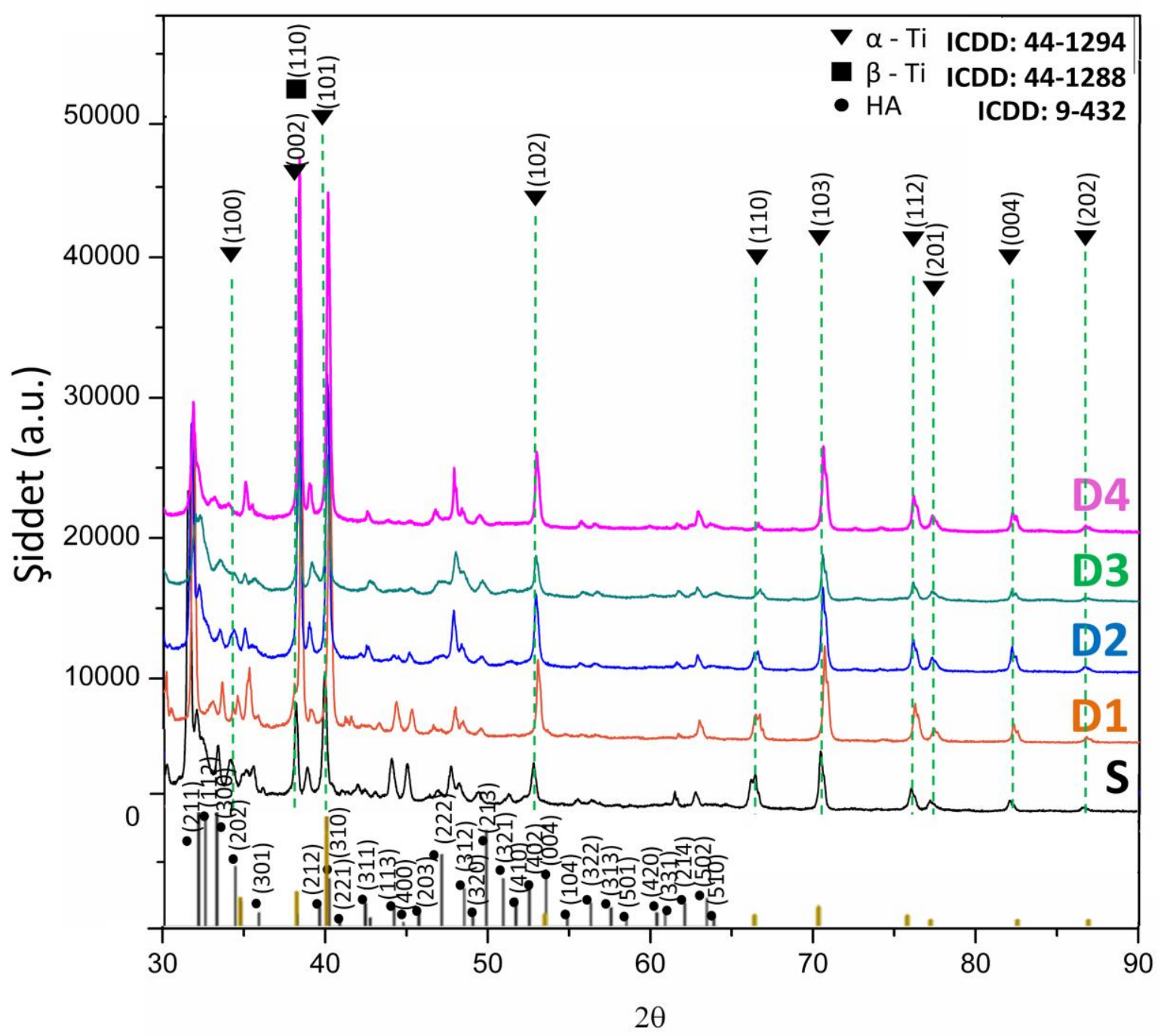

Şekil 6. Farklı oranlarda DEA içeren ve DEA içermeyen numunelere ait XRD grafiği

Figure 6. XRD graphs of samples with different ratios of DEA and without DEA 
gözlemlenmemiştir. $35^{\circ}$ ve $48-50^{\circ}$ arasında bulunan pikler incelendiğinde, DEA miktarının artması ile HA tabakasina ait piklerin şiddetlerinde bir artış gözlemlenmiştir. Mevcut artışı bu piklerde daha net gözlemlenebilmesinin sebebi, pik şiddetlerinin diğer piklere kıyasla daha yüksek olmasıdır. Kaplanmış tüm numunelerde $\mathrm{HA} \quad \mathrm{Ca} / \mathrm{P}$ stokiyometrik oranı 1,67 olacak şekilde elde edilebilmiş olup ICDD kart numarası 9-432'dir. Yapılan çalışmalarda sol-jel ile üretim sırasında oluşabilecek monotit veya trikalsiyum fosfat gibi bazı yapılar mevcuttur. $\mathrm{Bu}$ yapılar $\mathrm{Ca} / \mathrm{P}$ stokiyometrik oranlarına göre farklılık göstermekte olup bu oran 1.2-2.0 arasında iken hidroksiapatit oluşumu gerçekleşmekte ve bu yapı kararlı olmaktadır [5]. A. Lugovskoy ve S. Lugovskoy [5], yaptıkları çalışmada okside edilmiş titanyum yüzeyler üzerinde $\mathrm{HA}$ tabakalar elde etmeyi amaçlamış ve bu çalışmada elde edilebilecek kalsiyum fosfat fazlarının $\mathrm{CaHPO}_{4} \cdot 2 \mathrm{H}_{2} \mathrm{O}$ (dikalsiyum fosfat), $\mathrm{Ca}_{3}\left(\mathrm{PO}_{4}\right)_{2} \quad$ (Trikalsiyum fosfat), $\mathrm{Ca}_{4} \mathrm{P}_{2} \mathrm{O}_{9}$ (Tetrakalsiyum fosfat) ve $\mathrm{Ca}_{10}\left(\mathrm{PO}_{4}\right)_{6}(\mathrm{OH})_{2}$ (Hidroksiapatit, HA) olduğunu vurgulamıştır [5]. Anjaneyulu vd. [22], farklı sicakliklarda kalsine ederek HA tozları üretmiş ve $1000{ }^{\circ} \mathrm{C}$ sicaklığın altında kalsine ettiği toz numunelerde saf HA elde edebildiğini vurgulamıştır. Şekil 6'da gözlemlenen HA pikleri, bu çalışmada Anjaneyulu vd.'nin tespit ettikleri HA pikleri ile de örtüşmektedir.

Şekil 7'de SBF içinde uygulanan elektrokimyasal potansiyodinamik korozyon testi sonucunda elde edilen polarizasyon eğrileri verilmiştir. Grafik incelendiğinde tüm numunelerde homojen korozyon gözlemlendiği ve lokal korozyona rastlanmadiğ gözlemlenmiştir. $S$ numunesinde beklendiği üzere diğer numuneler ile karşılaştırıldığında daha negatif korozyon potansiyeli ve daha düşük akım yoğunluğu görülmüştür. Diğer bir yandan D1 numunesine yani en düşük oranda DEA içeren kaplamaya ait eğrinin en yüksek potansiyel ve en yüksek korozyon akım yoğunluğu gösterdiği görülmektedir. Diğer eğriler incelendiğinde ise korozyon potansiyeli DEA miktarının en az olduğu D1 numunesinde optimum seviyede olduğu ve artan değerlerde lineer olmasa da durumu negatif etkilediği görülmüştür.

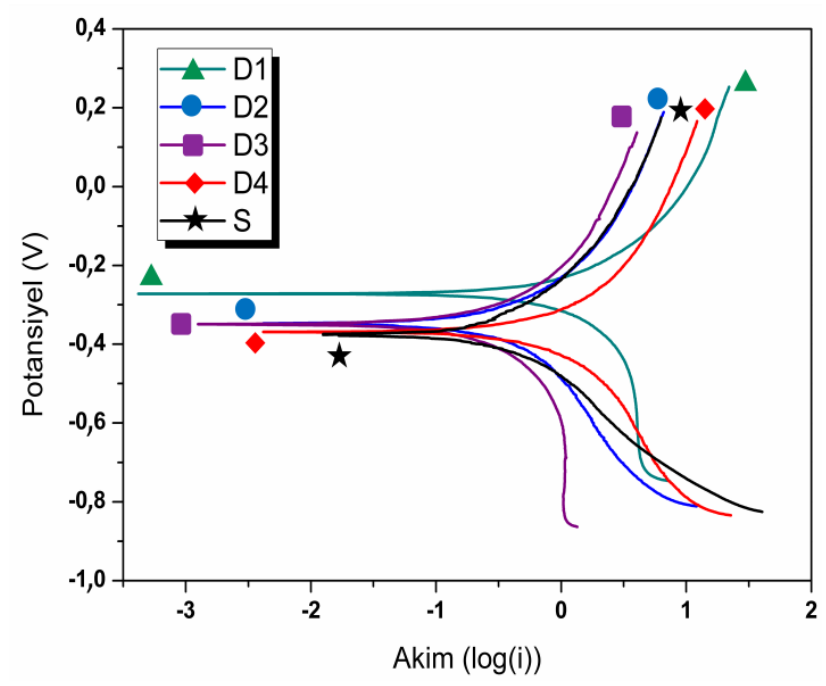

Şekil 7.SBF içinde elde edilen Tafel polarizasyon ĕgrileri

Figure 7. Tafel polarization curves obtained in SBF

Tablo 1. Potansiyodinamik polarizasyon sonuçları

Table 1. Potentiodynamic polarization results

\begin{tabular}{ccccc}
\hline Numune Ad1 & Ecorr $(\mathrm{V})$ & Rp $(\mathrm{KOhm})$ & Icorr $\left(\mu \mathrm{A} / \mathrm{cm}^{2}\right)$ & $\begin{array}{c}\text { Korozyon h1z1 } \\
(\mathrm{mm} / \mathrm{y} 1)\end{array}$ \\
\hline S & $-0,42071$ & 132,5579 & 0,598243 & 0,05288 \\
D1 & $-0,24636$ & 62,7881 & 3,099883 & 0,27399 \\
D2 & $-0,41794$ & 156,7469 & 0,707637 & 0,062547 \\
D3 & $-0,25384$ & 262,747 & 0,973493 & 0,086043 \\
D4 & $-0,40474$ & 78,23247 & 1,51601 & 0,133997 \\
\hline
\end{tabular}


Tablo 1. incelendiğinde Ecorr değerlerinde D1 ve D3 numunelerinin sifira daha yakın değerlerde çıkması ve Icorr değerlerinin diğer numunelere kıyasla daha yüksek olması korozyon dayanımlarının daha yüksek olduğu anlamına gelmektedir [23]. Bu durumda diğer numunelere ait eğriler ile karşılaştırıldığında D1 ve D2 numunelerinin daha iyi korozyon direncine sahip olduğu söylenebilir. D4 numunesinin korozyon dayanımının beklenenin aksine düşük olmasının sebebi ise SEM görüntülerinde de gözlemlenen mikro çatlaklardır. DEA miktarının arttırması kaplama kalınlıklarının artmasına bu durum kaplamaların yüzeye tutunabilirliğinin azalmasına ve mikro çatlakların oluşmasına neden olmuş ve dolayısı ile korozyon dayanımını azaltmıştır.

\section{Sonuçlar}

Yapılan çalışmada Ti6Al4V altlık malzemeler üzerine katkı maddesi içermeyen ve sırasıyla hacimce $\% 1,2,3$ ve 4 oranlarında DEA içerecek şekilde HA içerikli kaplamalar yapılmış ve yapılan bu kaplamalarda DEA miktarının yüzey morfolojisine ve kaplamaların yapay vücut sıvısı içinde korozyon dayanımlarına etkileri incelenmiştir. Yapılan incelemeler sonucunda DEA miktarının artması ile sol-jel yönteminin dezavantajlarından birini oluşturan ve sol-jel yöntemi ile kaplanmış kaplamalarda korozyon dayanımlarını genel olarak negatif yönde etkilediği düşünülen çatlaklı yapılar giderilmiş, altlık yüzeylerinde daha yoğun ve daha homojen bir kaplama tabakası elde edilmesi sağlanmıştır. Kaplama kalınlıkları, eklenen DEA miktarının artması ile artmıştır. Fakat DEA miktarının artması beklenenin aksine korozyon dayanımını arttırmamıştır. Kaplama solüsyonuna bir miktar DEA eklenmesi yüzey morfolojisini ve korozyon dayanımını iyileştirmiş fakat \%4 DEA içeren numunede mikro çatlakların oluşmasına ve bu nedenle korozyon dayanımının düşmesine neden olduğu gözlemlenmiştir.

\section{Teşekkür}

Bu çalışma MCBÜ Bilimsel Araştırma Projeleri Koordinasyon Birimi tarafindan 2018-096 numaralı proje ile desteklenmiştir. Yazarlar finansal destek için MCBÜ Bilimsel Araştırma Projeleri Koordinasyon Birimi'ne teşekkür ederler.

\section{Kaynaklar}

[1] Li, Q., Yang, W., Liu, C., Wang, D., Liang, J., (2017). Correlations between the growth mechanism and properties of micro-arc oxidation coatings on titanium alloy: Effects of electrolytes. Surface \& Coatings Technology, 316, 162-170.

[2] Miranda G., Sousa, F., Costa, M. M., Bartolomeu, F., Silva, F. S., Carvalho, O., (2019). Surface design using laser technology for Ti6Al4V-hydroxyapatite implants. Optics \& Laser Technology, 109, 488-495.

[3] Liu, X., Chu, P. K., Ding, C., (2004). Surface modification of titanium, titanium alloys, and related materials for biomedical applications, Materials Science and Engineering: R, Reports, 47, 49-121.

[4] Yılmaz, B., Evis, Z., (2014). Titanyum Alaşımının Selenat Eklenmiş Hidroksiapatit ile Kaplanması. Afyon Kocatepe Üniversitesi Fen ve Mühendislik Bilimleri Dergisi, 14, 335-339.

[5] Lugovskoy, A., Lugovskoy, S., (2014). Production of hydroxyapatite layers on the plasma electrolytically oxidized surface of titanium alloys, Materilas Science and Engineering: C, 43, 527-532.

[6] He, D., Du, J., Liu, P., Liu, X., Chen, X., Li, W., Zhang, K., Ma, F., (2019). Influence of EDTA-2Na on the hydroxyapatite coating deposited by hydrothermal-electrochemical method on Ti6Al4V surface, Surface and Coatings Technology, 365, 242-247.

[7] Huang, H., Lan, P.-H., Zhang, Y.-Q., Li, X.-K., Zhang, X., Yuan, C. F, Zheng, X. B., Guo, Z., (2015). Surface characterization and in vivo performance of plasma-sprayed hydroxyapatitecoated porous Ti6Al4V implants generated by electron beam melting, Surface and Coatings Technology, 283, 80-88.

[8] Garcia-Casas, A., Aguilera-Correa, J. J., Mediero, A., Esteban, J., Jimenez-Morales, A., (2019). Functionalization of sol-gel coatings with organophosphorus compounds for prosthetic devices, Colloids and Surfaces B: Biointerfaces, 181, 973-980. 
[9] Ayday, A., (2018). Mikro Ark oksidasyon işlemi ile kaplanan Ti6Al4V alaşımının yüzey karakterizasyonu ve korozyon özelliklerinin incelenmesi, Sakarya Üniversitesi Fen Bilimleri Enstitüsü Dergisi, 22, 2, 243-247.

[10] Ke, D., Vu, A. A., Bandyopadhyay, A., Bose, S., (2019). Compositionally graded doped hydroxyapatite coating on titanium using laser and plasma spray deposition for bone implants, Acta Biomaterialia, 84, 414-423.

[11] Pawlik, A., Ur Rehman, M. A., Nawaz, Q., Bastan, F. E., Sulka, G. D., Boccaccini, A. R., (2019). Fabrication and characterization of electrophoretically deposited chitosanhydroxyapatite composite coatings on anodic titanium dioxide layers, Electrochemica Acta, 307, 465-473.

[12] Ban, S., Hasegava, J., (2002). Morphological regulation and crystal growth of hydrothermalelectrochemically deposited apatite, Biomaterials, 23, 14, 2965-2972.

[13] Toygun, Ş., Köneçoğlu, G., Kalpaklı, Y., (2013). General Principles of sol-gel, Journal of Engineering and Natural Sciences Mühendislik ve Fen Bilimleri Dergisi, 31, 456-476.

[14] Batebi, K., Abbasi Khazaei, B., Afshar, A., (2018). Characterization of sol-gel derived silver/flourhydroxyapatite composite coatings on titanium substrate, Surface and Coatings Technology, 352, 522-528.

[15] Nikolić, L., Radonjić, L., (1994). Effect of drying control chemical additives in Sol-Gel-Glass Monolith processing. Ceramics International, 20, 5, 309-313.
[16] Uchida, N., Ishiyama, N., Kato, Z., Uematsu, K., (1994). Chemical effects of DCCA to the sol-gel reaction process. Journal of Materials Science, 29, 19, 5188-5192.

[17] Robertson, S. F., Bandyopadhyay, A., Bose, S., (2019). Titania nanotube interface to increase adhesion strength of hydroxyapatite sol-gel coatings on Ti-6Al-4V, Surface and Coatings Technology, 372, 140-147.

[18] Haddow, D. B., Kothari, S., James, P. F., Short, R. D., Hatton, P. V., van Noort, R., (1996). The formation and characterization of sol-gel titania films, Biomaterials, 17, 501-507.

[19] Wang, D., Bierwagen, G., (2009). Sol-gel coatings on metals for corrosion protection, Progress in Organic Coatings, 64, 4, 327-338.

[20] Pasinli, A., Yuksel, M., Celik, E., Sener, S., Tas, A. C., (2010). A new approach in biomimetic synthesis of calcium phosphate coatings using lactic acid-Na lactate buffered body fluid solution. Acta Biomaterialia, 6, 6, 2282-2288.

[21] Arafat, M. M., Haseeb, A. S. M. A., Akbar, S. A., (2015). Growth and characterization of the oxide scales and core/shell nanowires on Ti-6Al-4V particles during thermal oxidation, Ceramics International, 41, 3, 4401-4409.

[22] Anjaneyulu, U., Priyadarshini, B., Arul Xavier Stango, S., Chellappa, M., Geetha, M. Vijayalakshmi, U., (2017). Preparation and characterisation of sol-gel-derived hydroxyapatite nanoparticles and its coatings on medical grade Ti6Al-4V alloy for biomedical applications, Materials Technology, 32, 13, 800-814.

[23] McCafferty, E., (2010) Introduction to Corrosion Science, Springer Press, Virginia. 